\section{D) Check for updates}

Cite this: Food Funct., 2020, 11 2208

Received 23rd December 2019, Accepted 15th February 2020

DOI: $10.1039 /$ c9fo03050f

rsc.li/food-function

\title{
Castanea sativa male flower extracts as an alternative additive in the Portuguese pastry delicacy "pastel de nata"
}

\author{
Cristina Caleja, ${ }^{a, b}$ Lillian Barros, (iD a João C. M. Barreira, (ID *a Marina Soković, (DD c \\ Ricardo C. Calhelha, ${ }^{a}$ Albino Bento, ${ }^{a}$ M. Beatriz P. P. Oliveira (D) b ${ }^{b}$ and \\ Isabel C. F. R. Ferreira (iD *a
}

\begin{abstract}
Replacing artificial additives by natural compounds is a current trend in the food industry. In addition to their preserving effect, naturally obtained ingredients often exhibit important levels of bioactivities. Generally, plant species represent better sources of natural ingredients, since their compounds are less prone to causing unpleasant taste or odour. Chestnut male flower (CMF) was reported to have high antioxidant and antimicrobial activities. Hence, it was tested as an alternative to potassium sorbate in the most treasured Portuguese delicacy: "pastel de nata". Different nutritional, chemical, physical and bioactive parameters were compared in two different periods: baking day and two days after baking. All samples presented similar nutritional and chemical profiles, but those added with CMF revealed higher contents of reducing agents and radical scavengers. Accordingly, the newly obtained formulation is expected to have better effects on consumers' health, maintaining the chemical characteristics, besides rendering a novel, economically profitable, application to CMF.
\end{abstract}

\section{Introduction}

The main concerns about pastry products are currently focused in the improvement of nutritional composition, aiming to reduce fat and sugar contents. ${ }^{1,2}$ Another current consumers' trend regards the preference for food products with "cleaner" labels, free as much as possible of artificial additives, owing to their putatively deleterious health effects. ${ }^{3}$ Under this new scenario, the extracts and bioactive compounds obtained from plants, which naturally show antioxidant activity and considerable effectiveness against several microbial strains, have been increasingly used to replace artificial additives. ${ }^{3,4}$

These natural ingredients, simultaneously acting as preserving and functionalizing agents, are particularly valued when obtained from plant species, especially due to the lower probability of affecting the organoleptic properties of the final

\footnotetext{
${ }^{a}$ Centro de Investigação de Montanha (CIMO), Instituto Politécnico de Bragança, Campus de Santa Apolónia, 5300-253 Bragança, Portugal. E-mail: iferreira@ipb.pt, jbarreira@ipb.pt; Tel: +351-273-303219, +351-273-303903; Fax: +351-273-325405 ${ }^{b}$ REQUIMTE/LAQV, Faculty of Pharmacy, University of Porto, Rua Jorge Viterbo Ferreira, no. 228, 4050-313 Porto, Portugal

${ }^{c}$ University of Belgrade, Department of Plant Physiology, Institute for Biological Research "Siniša Stanković", Bulevar Despota Stefana 142, 11000 Belgrade, Serbi
}

product, or, in case they do, the potential changes tend to be pleasant to the consumers. 5,6

Chestnut male flowers (CMF) are an important by-product resulting from the most important crop in the northeast of Portugal (representing also a relevant economic source nationwide and in other European countries such as Spain, Italy or Turkey). ${ }^{7}$ Besides being naturally abundant, several authors describe the excellent antioxidant, antimicrobial and antitumor properties of the infusions and decoctions of CMF, which, among other functions, might be important for food preservation, ${ }^{8,9}$ as previously verified in other food products functionalized with CMF extracts. ${ }^{10-13}$

In the current study, we have considered the hypothesis of using an aqueous extract of CMF as a preserving agent in the most acknowledged Portuguese pastry delicacy, globally known as "pastel de nata". This custard tart was created in the beginning of the XVIII century and has been recently recognized as the $15^{\text {th }}$ tastiest delicacy in the world. ${ }^{14}$ Owing to its phenolic richness, it is expected that the incorporation of these natural extracts may provide antioxidant and antimicrobial properties to "pastel de nata". In addition to verifying the potential improvement in their bioactivity, samples were also evaluated for different chemical and nutritional parameters, in all cases measured on the baking day (samples were baked after being kept frozen for 6 months) and 2 days after, the maximum period during which "pastel de nata" maintains its freshness. 


\section{Materials and methods}

\subsection{Characterization of chestnut male flower extracts}

2.1.1. Preparation. The male flowers of Castanea sativa Mill. (cv. Judia) were collected in the Northeast of Portugal (Oleiros, Bragança, Trás-os-Montes) from the orchard's ground (the natural flower drop occurs around July-August). The CMF extracts rich in phenolic compounds were obtained by heatassisted extraction. ${ }^{15}$ In brief, the dried powdered flower samples $(600 \mathrm{mg})$ were extracted with $20 \mathrm{~mL}$ of a water: ethanol mixture (33:67), for 20 minutes at $25{ }^{\circ} \mathrm{C}$. Afterwards, samples were lyophilized and stored in a desiccator at room temperature (average $25^{\circ} \mathrm{C}$ ), protected from light, until further analysis.

2.1.2. Quantification of radical scavengers and reducing agents. To determine the corresponding $\mathrm{EC}_{50}$ values (sample concentration providing $50 \%$ of scavenging activity or 0.5 of absorbance in the reducing power assay), serial dilutions of the freeze-dried extract re-dissolved in ethanol were prepared.

Four spectrophotometric assays were used: ${ }^{16}$

DPPH radical-scavenging activity $(515 \mathrm{~nm})$ was calculated after measuring the discolouration of a methanolic solution of $\mathrm{DPPH}\left(6 \times 10^{-5} \mathrm{M}\right)$ according to the following equation:

$$
\left[\left(A_{\mathrm{DPPH}}-A_{\mathrm{S}}\right) / A_{\mathrm{DPPH}}\right] \times 100,
$$

where $A_{\mathrm{S}}$ is the absorbance of the solution containing the sample at $515 \mathrm{~nm}$, and $A_{\mathrm{DPPH}}$ is the absorbance of the DPPH solution.

Reducing power (690 nm) was evaluated considering the capacity to reduce ferric $\left(\mathrm{Fe}^{3+}\right)$ iron to its ferrous $\left(\mathrm{Fe}^{2+}\right)$ form. Reducing power and DPPH scavenging activity were both measured using microplate assays (ELX800 microplate reader, Bio-Tek Instruments, Inc., Winooski, VT, USA).

The capacity to inhibit $\beta$-carotene bleaching induced by linoleate radicals was evaluated considering the samples' capacity to neutralize those free radicals according to the formula: $\beta$-carotene absorbance after $2 \mathrm{~h}$ of assay/initial absorbance $\times 100$.

Absorbance was measured at $470 \mathrm{~nm}$ (Analytik 200-2004 spectrophotometer, Jena, Germany).

Lipid peroxidation inhibition (532 nm) was evaluated in brain tissue (obtained from Sus scrofa) homogenates by evaluating the capacity of samples to prevent the formation of thiobarbituric acid reactive substances (TBARS) and their further complexation with malondialdehyde (MDA-TBA). The inhibition percentage was calculated as $[(A-B) / A] \times 100 \%$, where $A$ and $B$ were the absorbance of the control and the sample solution, respectively.

Trolox was used as the positive control in all assays.

2.1.3. Cytotoxicity evaluation. Cytotoxicity was evaluated in a porcine hepatocyte cell line using a liver provided by a certified slaughterhouse. ${ }^{17}$ Cell proliferation was achieved by sequential sub-cultures (96-well plates), timely monitored with a phase-contrast microscope. Cells were cultured in Dulbecco's modified Eagle's medium (added with foetal bovine serum: 10\%, penicillin: $100 \mathrm{U} \mathrm{mL}^{-1}$ and streptomycin: $100 \mu \mathrm{g} \mathrm{mL}^{-1}$ ).
Cell proliferation was evaluated following the sulforhodamine $\mathrm{B}$ assay. The extract concentration able to reduce cellular proliferation by $50 \%\left(\mathrm{GI}_{50}, \mu \mathrm{g} \mathrm{mL}^{-1}\right)$ was used as the cytotoxicity indicator. A positive control (ellipticine) was also tested.

2.1.4. Evaluation of antimicrobial properties. The CMF extracts were tested against four Gram-negative bacteria: Escherichia coli (ATCC 35210), Pseudomonas aeruginosa (ATCC 27853), Salmonella enterica serovar typhimurium (ATCC 13311), Enterobacter cloacae (ATCC 35030), and Gram-positive bacteria: Staphylococcus aureus (ATCC 6538), Bacillus cereus (clinical isolate), Micrococcus flavus (ATCC 10240), and Listeria monocytogenes (NCTC 7973). Two antibacterial activity indicators were considered: minimum inhibitory and minimum bactericidal concentrations (MIC and $\mathrm{MBC}$, respectively) were determined and compared with those obtained with positive controls (streptomycin and ampicillin). The antibacterial assays were carried out by the disc-diffusion and microdilution method and following a previously described procedure. ${ }^{18}$

The antifungal activity was also evaluated by the microdilution method in eight different species: Aspergillus fumigatus (ATCC 1022), Aspergillus ochraceus (ATCC 12066), Aspergillus versicolor (ATCC 11730), Aspergillus niger (ATCC 6275), Penicillium funiculosum (ATCC 36839), Penicillium ochrochloron (ATCC 9112), Trichoderma viride (IAM 5061), and Penicillium verrucosum var. cyclopium (food isolate). In line with the evaluation of antibacterial activity, two antifungal indicators were also considered: ${ }^{19}$ MIC and minimum fungicidal concentration (MFC), which, in this case, were compared with those obtained with the positive controls bifonazole and ketoconazole.

2.1.5. Identification of phenolic compounds by HPLC-DAD. The extract was filtered $(0.22 \mu \mathrm{m}$ disposable LC filter disk) before chromatographic analysis (HPLC-DAD-ESI/ MSn, Dionex Ultimate 3000 UPLC, Thermo Scientific, San Jose, CA, USA). ${ }^{20}$ Detection was carried out using a diode array detector (DAD) (280, 330, and $370 \mathrm{~nm}$ were the selected wavelengths) and the obtained data were acquired with an Xcalibur® data system (Thermo Finnigan, San Jose, CA, USA). Identification of phenolic compounds (specifically trigalloylHHDP-glucoside and quercetin-3-O-glucuronide) was made considering UV spectra and retention times, and by comparing with authentic standards (when available). Peak areas (using the baseline to valley integration with the baseline projection mode) were used to quantify both compounds, considering the calibration curves (concentration range: $2.5-100 \mu \mathrm{g} \mathrm{mL}^{-1}$ ) of standard compounds: ellagic acid $(y=26719 x-317255$; $\left.R^{2}=0.999\right)$ and quercetin 3-O-glucoside $(y=34843 x-160173$; $\left.R^{2}=0.999\right)$.

\subsection{Characterization of "pastéis de nata"}

2.2.1. Preparation. To prepare the "pastel de nata", the traditional base recipe was followed: $200 \mathrm{ml}$ of custard were mixed with $50 \mathrm{ml}$ of milk. Then, $6 \mathrm{egg}$ yolks, $100 \mathrm{~g}$ of sugar and 1 tablespoon of wheat flour were added and mixed with a hand mixer at $450 \mathrm{~W}$ (MFQ 3540, Bosch, Munich, Germany). This recipe corresponded to the control "pastel de nata" 
(PNC), while other batches were prepared by adding $0.54 \mathrm{~g}$ of CMF extracts (PNCL) or $0.54 \mathrm{~g}$ of potassium sorbate (PNPS) to sugar before mixing it with the cream. Some flavouring ingredients are commonly used, including lemon zest or cinnamon sticks; however, we opted to strictly follow the traditional recipe, avoiding any kind of interference in the evaluation of bioactivity. The mixture was slowly heated, under continuous stirring, until it started boiling. After cooling down, it was poured in individual forms previously filled with puff pastry (purchased from a local supermarket) and frozen for 6 months. Afterwards, samples were defrosted and baked at $250{ }^{\circ} \mathrm{C}$ (oven HE-635, Teka, Haiger, Germany) for 15 minutes. Three different lots (PNC, PNCL and PNPS) were prepared: 10 "pastéis de nata" per lot, further divided into 2 groups of 5 "pastéis de nata" for each assayed time ( $t 0$ and $t 2$ ). After baking, all samples were lyophilized, milled and analysed (in triplicate), immediately after preparation and after two days of storage (samples were packed in a sealed polyethylene bag and stored in a refrigerator).

2.2.2. Evaluation of nutritional properties. The contents of protein, fat and ash were determined following the AOAC methods. ${ }^{21}$ Carbohydrate content was calculated considering the difference among $100 \mathrm{~g}$ and the levels ( $\mathrm{g}$ per $100 \mathrm{~g}$ ) of water, protein $(N \times 5.7)$, fat and ash. The energy value was calculated as: Energy (kcal) $=4 \times($ g proteins $+\mathrm{g}$ carbohydrates $)+$ $9 \times(\mathrm{g}$ lipids). The energy value is also presented in $\mathrm{kJ}$ by multiplying the energy (kcal) by 4.19 .

2.2.3. Fatty acid profile. Fatty acids were determined by Soxhlet extraction with hexane and derivatization with methanol (to produce methyl esters) by gas-liquid chromatography with flame ionization detection (FID). ${ }^{16}$ The analysis was carried out with a DANI model GC 1000 instrument equipped with a split/splitless injector, a FID at $260{ }^{\circ} \mathrm{C}$ and a ZebronKame column $(30 \mathrm{~m} \times 0.25 \mathrm{~mm}$ ID $\times 0.20 \mu \mathrm{m}$ df, Phenomenex, Lisbon, Portugal). The oven temperature program was as follows: the initial temperature of the column was $100{ }^{\circ} \mathrm{C}$, held for $2 \mathrm{~min}$, then a $10{ }^{\circ} \mathrm{C} \mathrm{min}^{-1}$ ramp to $140{ }^{\circ} \mathrm{C}, 3{ }^{\circ} \mathrm{C} \mathrm{min}^{-1}$ ramp to $190{ }^{\circ} \mathrm{C}$, and $30^{\circ} \mathrm{C} \min ^{-1}$ ramp to $260{ }^{\circ} \mathrm{C}$ and held for

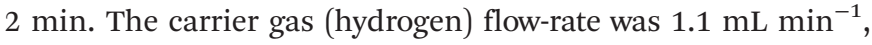
measured at $100{ }^{\circ} \mathrm{C}$. Split injection $(1: 50)$ was carried out at $250{ }^{\circ} \mathrm{C}$. Fatty acid identification was made by comparing the relative retention times of FAME (mixture of thirty-seven fatty acids) peaks from samples with standards. The results were recorded and processed using the Clarity DataApex 4.0 Software and expressed in relative percentage of each fatty acid.

2.2.4. Free sugars. The defatted samples remaining in the Soxhlet cartridges after the procedure described in 2.2.3 were extracted $\left(80{ }^{\circ} \mathrm{C}, 90 \mathrm{~min}\right)$ with ethanol: water $(80: 20)$. After removing ethanol, samples were filtered and analysed by HPLC coupled to a refraction index (RI) detector. ${ }^{22}$ Sugars were identified by comparison with commercial standards $(\mathrm{D}(-)$-fructose, $\mathrm{D}(+)$-sucrose, $\mathrm{D}(+)$-glucose, $\mathrm{D}(+)$-trehalose and $\mathrm{D}(+)$-raffinose pentahydrate). The quantification was made following the internal standard (melezitose) method, and the results were given in $\mathrm{g}$ per $100 \mathrm{~g}$ of "pastel de nata".
2.2.5. Evaluation of CIE parameters and the $\mathrm{pH}$ value. Colour parameters were measured (before and after baking) in triplicate in each "pastel de nata" (colorimeter CR-400, Konica Minolta Sensing Inc., Tokyo, Japan). Illuminate $\mathrm{C}$ was selected (diaphragm aperture: $8 \mathrm{~mm}$ ) after calibration against a standard white tile. The CIE $L^{*}$ (lightness), $a^{*}$ (greenness/redness) and $b^{*}$ (blueness/yellowness) colour space values were recorded using "Spectra Magic Nx" (version CM-S100 W 2.03.0006). ${ }^{23}$

Likewise, $\mathrm{pH}$ measurements were done before and after baking. Values were obtained in triplicate directly in the samples (HI 99161, pH-meter, Hanna Instruments, Woonsocket, Rhode Island, USA).

2.2.6. Quantification of radical scavengers and reducing agents. Using a previously described procedure, ${ }^{24} 3 \mathrm{~g}$ of each sample (lyophilized) were extracted sequentially with a mixture of water: ethanol $(33: 67)$ for $1+1$ hour. After filtering and taking the samples to dryness, the obtained powders were dissolved at a final concentration of $200 \mathrm{mg} \mathrm{mL}^{-1}$, which was successively diluted to prepare the working range (10 to $200 \mathrm{mg}$ $\mathrm{mL}^{-1}$ ) concentrations used to evaluate the 2,2-diphenyl-1picrylhydrazyl (DPPH) radical-scavenging activity and reducing power (RP) as described in section 2.1.2.

2.2.7. Toxicity assay. For the evaluation of toxicity, the samples were subjected to sulforhodamine B assay, as described in section 2.1.3.

2.2.8. Phenolic compound quantification in "pastéis de nata". The major phenolic compounds were monitored during storage in order to determine if any degradation was observed. Trigalloyl-HHDP-glucoside (main ellagitannin) and quercetin3-O-glucuronide (main flavonoid) were detected and quantified through an HPLC system as described in section 2.1.5.

\subsection{Statistical analysis}

The statistical tests were done with IBM SPSS Statistics (v. 22) for Windows (IBM Corp., Armonk, NY, USA), considering a 5\% significance level. Results were expressed as mean \pm standard deviation (different decimal places were shown according to the standard deviation magnitude obtained in each case), except for antimicrobial assays.

Results were compared through the general linear model (GLM) procedure. Dependent variables were analysed by 2-way ANOVA (type III sums of squares) considering the "pastel de nata" formulation (PN) and storage time (ST) as the statistical factors. If a statistically significant interaction among factors was found, the observed differences were verified in the estimated marginal means plots. Otherwise, means were compared using Tukey's multiple comparison test, after a previous verification of variances' homogeneity (Levene's test).

In addition to the previous comparison case-by-case, results were overall assessed through a linear discriminant analysis (LDA) to better understand the true effects of PN and ST. The stepwise approach was used, based on the Wilks' $\lambda$ test (probabilities of $F$ : 3.84 for variable selection, 2.71 for variable removal). It was intended to determine which independent variables contributed more to the differences in the average 
score profiles of PN conjugated with ST. The significance of the canonical discriminating functions was verified by the Wilk's $\lambda$ test and the model performance was evaluated by the leaving-one-out cross validation procedure.

\section{Results and discussion}

\subsection{Characterization of the chestnut male flower extract}

The water: ethanol $(33: 67)$ extracts of CMF were initially assayed for their radical scavenger and reducing agent contents (Table 1), showing particularly good results in the cases of $\beta$-carotene bleaching inhibition $\left(\mathrm{EC}_{50}=32 \mu \mathrm{g} \mathrm{mL}^{-1}\right.$ extract) and TBARS formation inhibition $\left(\mathrm{EC}_{50}=13 \mu \mathrm{g} \mathrm{mL}^{-1}\right.$ extract), which might indicate a higher suitability of CMF extracts towards lipophilic environments. In general, the obtained $\mathrm{EC}_{50}$ values are lower (higher antioxidant activity) than those obtained previously in aqueous extracts of $\mathrm{CMF}^{8,25}$

The antibacterial activity (Table 1) was significant, since CMF gave similar (or even lower) MIC and MBC to ampicillin for all bacterial species, except Staphylococcus aureus and
Micrococcus flavus. Among the tested bacteria, CMF was particularly effective against Bacillus cereus, as indicated by the lowest MIC and MBC values obtained in the assays conducted with these species. The MIC and MBC values are in the same range as those obtained with infusions and decoctions of $\mathrm{CMF}^{9}$

A similar level of activity was found among fungal species. In fact, the antifungal activity of CMF was higher than that exhibited by ketoconazole, particularly against Aspergillus ochraceus and Penicillium ochrochloron, as evidenced by the lower MIC (twenty times lower in the case of A. ochraceus) obtained with CMF. In general, the water: ethanol extracts studied herein showed higher activity than the corresponding decoctions and infusions. ${ }^{9}$

The detected bioactivity might be related with the phenolic profile of CMF, which has been reported in detail in a previous study. ${ }^{15}$ As described previously, fourteen phenolic compounds were detected, divided into seven hydrolysable tannins and seven flavonoids. Among hydrolysable tannins, trigalloyl-HHDPglucoside was the major compound $(33.2 \pm 0.4)$, while myricetin-3-O-glucoside $(6.8 \pm 0.4)$ stood out as the major flavonoid.

Table 1 Radical scavenging and reducing capacity (values presented as mean \pm standard deviation) and antimicrobial activity of the chestnut male flower (CMF) extract

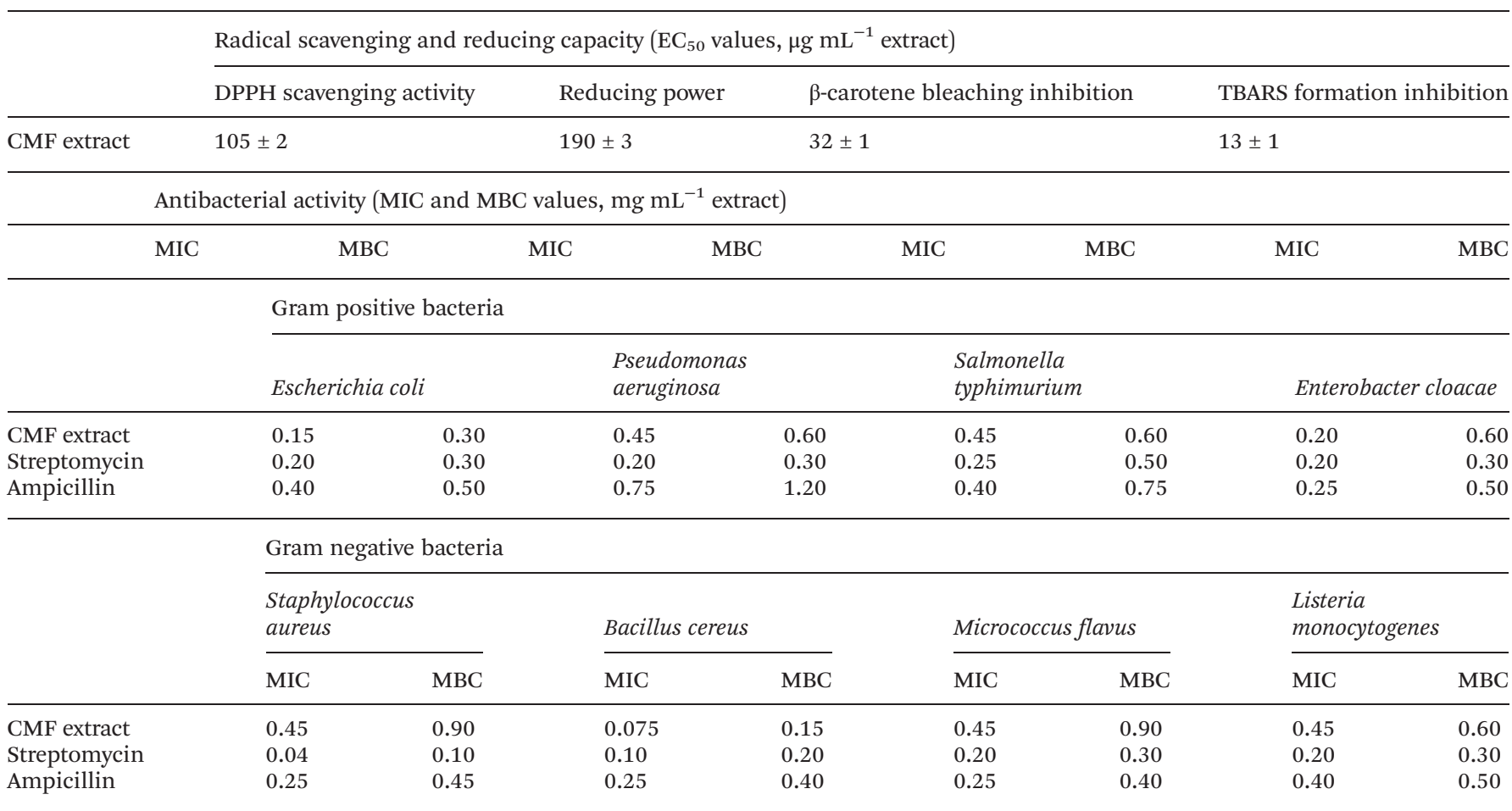

Antifungal activity (MIC and MFC values, $\mathrm{mg} \mathrm{mL}^{-1}$ extract)

\begin{tabular}{|c|c|c|c|c|c|c|c|c|c|c|c|c|c|c|c|c|}
\hline & \multicolumn{2}{|c|}{$\begin{array}{l}\text { Aspergillus } \\
\text { fumigatus }\end{array}$} & \multicolumn{2}{|c|}{$\begin{array}{l}\text { Aspergillus } \\
\text { ochraceus }\end{array}$} & \multicolumn{2}{|c|}{$\begin{array}{l}\text { Aspergillus } \\
\text { versicolor }\end{array}$} & \multicolumn{2}{|c|}{$\begin{array}{l}\text { Aspergillus } \\
\text { niger }\end{array}$} & \multicolumn{2}{|c|}{$\begin{array}{l}\text { Penicillium } \\
\text { funiculosum }\end{array}$} & \multicolumn{2}{|c|}{$\begin{array}{l}\text { Penicillium } \\
\text { ochrochloron }\end{array}$} & \multicolumn{2}{|c|}{$\begin{array}{l}\text { Trichoderma } \\
\text { viride }\end{array}$} & \multicolumn{2}{|c|}{$\begin{array}{l}\text { Penicillium } \\
\text { verrucosum }\end{array}$} \\
\hline & MIC & MFC & MIC & MFC & MIC & MFC & MIC & MFC & MIC & MFC & MIC & MFC & MIC & MFC & MIC & MFC \\
\hline CMF & 0.10 & 0.15 & 0.075 & 0.15 & 0.30 & 0.60 & 0.075 & 0.15 & 0.04 & 0.90 & 0.30 & 0.60 & 0.45 & 0.60 & 0.30 & 0.60 \\
\hline Ketoconazole & 0.25 & 0.50 & 1.50 & 2.00 & 0.20 & 0.50 & 0.20 & 0.50 & 0.20 & 0.50 & 2.50 & 3.50 & 1.00 & 1.00 & 0.20 & 0.30 \\
\hline Bifonazole & 0.15 & 0.20 & 0.15 & 0.20 & 0.10 & 0.20 & 0.15 & 0.20 & 0.20 & 0.25 & 0.20 & 0.25 & 0.15 & 0.20 & 0.10 & 0.20 \\
\hline
\end{tabular}


Considering the profiled phenolic compounds and the detected bioactivity, CMF was hypothesized as a novel preservative with potential food application. Accordingly, it was incorporated in the Portuguese delicacy "pastel de nata" as a possible alternative to potassium sorbate. Both prepared formulations (added with CMF or potassium sorbate) were also compared with the traditional recipe (no additives included). After a 6 month storage period, samples were evaluated at the baking (after defrosting) day and 2 days after baking.

\subsection{Characterization of "pastel de nata" formulations}

In addition to the potential health-related benefits provided by the substitution of potassium sorbate by CMF, the new "pastel de nata" formulation was assayed to fulfil the contemporary consumers' preference towards food products free of synthetic compounds.

The prepared samples were compared considering two distinct sources of variability (factors), specifically "pastel de nata" formulation (PN) and storage time (ST). In addition to evaluating the individual effect of each factor, their interaction $(\mathrm{PN} \times \mathrm{ST})$ was also verified. For all parameters showing a significant $(p<0.050)$ interaction, the classification resulting from multiple comparison tests was not presented, since in those cases the discussion of results should be made based on the estimated marginal means (EMM) plots.

3.2.1. Nutritional parameters and free sugar profile. In what concerns the nutritional composition (Table 2), the significant $(p<0.050)$ differences found were mainly associated with the PN factor. On the other hand, ST was only significant in the case of sucrose, which tended to present higher contents in samples analysed on the baking day (36 g per $100 \mathrm{~g}$ ). However, the detected difference is more likely to be explained by a less effective sugar extraction in samples stored for 2 days than by some potential sucrose degradation, as no increase in glucose and fructose was observed along time (glucose and sucrose were also detected, but with contents lower than $0.1 \mathrm{~g}$ per $100 \mathrm{~g}$ ). The interaction among factors was significant in all cases except for protein and ash contents. Therefore, these were the single parameters where the statistical classification was possible, evidencing in both cases, higher contents in PNPS. In turn, PNCL tended to present a higher moisture value (28 $\mathrm{g}$ per $100 \mathrm{~g}$ ), but lower contents of fat (24 g per $100 \mathrm{~g}$ ), carbohydrates (38 g per $100 \mathrm{~g}$ ), sucrose (34 g per $100 \mathrm{~g}$ ) and, consequently, lower energy value (406 kcal per $100 \mathrm{~g})$.

The higher effect of PN is probably related with the fact that samples were stored for a short period (2 days). Nevertheless, despite the identified differences among PN formulations, their nutritional profile was generally similar, indicating (as it could be easily anticipated) that the incorporation of different additives did not cause any major difference in any of the assayed parameters.

3.2.2. Fatty acid profile. The fatty acid profiles were also characterized in order to determine any possible alterations (Table 3). In line with the results discussed in the former section, a significant interaction among ST and PN was also verified (in all fatty acids except myristoleic acid (C14:1) and palmitic acid (C16:0)), indicating that the putative effects of storage varied within each prepared formulation. Nevertheless, it was possible to identify some tendencies caused by each individual factor, particularly among different PN formulations, exempting the cases of myristic acid (C14:0) ( $p$-value $=$ 0.168), C14:1 ( $p$-value $=0.604)$ and palmitoleic acid $(\mathrm{C} 16: 1)$ ( $p$-value $=0.097)$. In contrast, ST had a significant effect only on palmitic (C16:0), oleic (C18:1n9) and linoleic (C18:2n6) acids (besides saturated (SFA), monounsaturated (MUFA) and polyunsaturated (PUFA) fatty acids).

For the previous reason, the statistical classification is only presented in the case of C16:0, which was lower in control samples and on the baking day.

Table 2 Nutritional composition (g per $100 \mathrm{~g} \mathrm{fw}$ ) and energy values for different "pastel de nata" formulations (PN) and storage times (ST). Results are presented as mean \pm standard deviation ${ }^{a}$

\begin{tabular}{|c|c|c|c|c|c|c|c|c|c|c|}
\hline & & Moisture & Fat & Protein & Ash & Carbohydrates & Sucrose & Trehalose & $\begin{array}{l}\text { Energy } \\
\text { kcal } 100 \mathrm{~g}^{-1} \mathrm{fw}^{-1}\end{array}$ & $\begin{array}{l}\text { Energy } \\
\text { kJ } 100 \mathrm{~g}^{-1} \mathrm{fw}^{-1}\end{array}$ \\
\hline \multirow[t]{3}{*}{ PN } & Control & $27 \pm 1$ & $25 \pm 1$ & $7.9 \pm 0.3 \mathrm{c}$ & $0.36 \pm 0.02 \mathrm{~b}$ & $39 \pm 1$ & $35 \pm 1$ & $3.0 \pm 0.2$ & $413 \pm 3$ & $1730 \pm 9$ \\
\hline & $\begin{array}{l}\text { Potassium sorbate } \\
\text { (E202) }\end{array}$ & $27 \pm 1$ & $25 \pm 1$ & $8.8 \pm 0.3 \mathrm{a}$ & $0.40 \pm 0.03 \mathrm{a}$ & $39 \pm 1$ & $36 \pm 1$ & $2.5 \pm 0.1$ & $414 \pm 3$ & $1734 \pm 10$ \\
\hline & $\begin{array}{l}\text { ANOVA } p \text {-value } \\
(n=18)^{b}\end{array}$ & $<0.001$ & $<0.001$ & $<0.001$ & $<0.001$ & $<0.001$ & $<0.001$ & $<0.001$ & $<0.001$ & \\
\hline \multirow[t]{3}{*}{ ST } & 0 days & $27 \pm 1$ & $25 \pm 1$ & $8.4 \pm 0.4$ & $0.37 \pm 0.04$ & $39 \pm 1$ & $36 \pm 1$ & $2.8 \pm 0.2$ & $410 \pm 5$ & $1718 \pm 18$ \\
\hline & 2 days & $27 \pm 1$ & $25 \pm 1$ & $8.4 \pm 0.5$ & $0.38 \pm 0.03$ & $39 \pm 1$ & $35 \pm 1$ & $2.7 \pm 0.3$ & $411 \pm 4$ & $1722 \pm 15$ \\
\hline & $\begin{array}{l}t \text {-Student } p \text {-value } \\
(n=27)^{c}\end{array}$ & 0.452 & 0.997 & 0.794 & 0.297 & 0.395 & 0.001 & 0.256 & 0.561 & 0.565 \\
\hline $\mathrm{PN} \times \mathrm{ST}$ & $p$-value $(n=54)^{d}$ & $<0.001$ & 0.005 & 0.248 & 0.533 & $<0.001$ & 0.009 & 0.030 & $<0.001$ & $<0.001$ \\
\hline
\end{tabular}

${ }^{a}$ The results presented for each PN include values measured in both ST; likewise, results for each ST were obtained considering the values measured in all PN formulations. ${ }^{b}$ If $p<0.050$, the corresponding parameter presented a significantly different value for at least one PN. ${ }^{c}$ If $p<$ 0.050 , the corresponding parameter presented a significantly different value for each ST. ${ }^{d} p<0.050$ indicates a significant interaction among factors, thereby precluding performing multiple comparison tests. fw - fresh weight. 


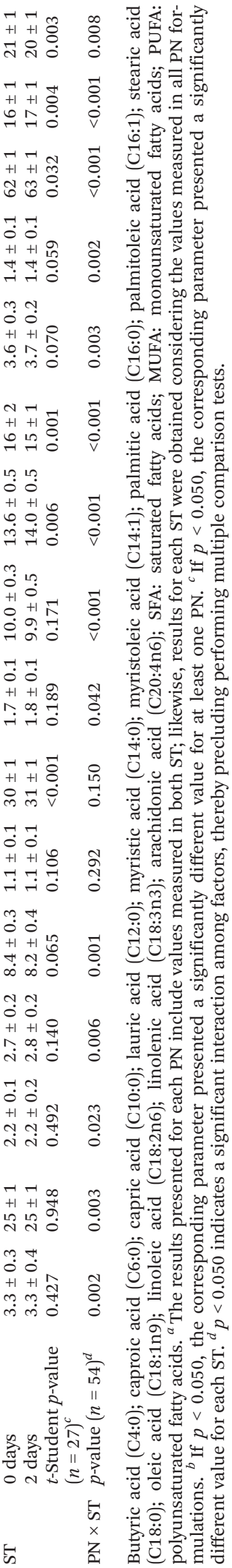

Despite the impossibility of presenting the statistical classification, some overall trends were found for specific fatty acids: butyric acid (C4:0), stearic acid (C18:0), oleic acid (C18:1n9), saturated and monounsaturated fatty acids presented higher percentages in PNPS, which, in turn, presented the lowest values of C18:2n6 and PUFA; control samples, on the other hand, had the lowest percentages of caproic acid (C6:0), palmitic acid (C16:0) and linolenic acid (C18:3n3) and the highest of lauric acid (C12:0); the most noticeable change in PNCL was the higher percentage of arachidonic acid (C20:4n6).

In what concerns the differences resulting from ST, stored samples were mostly characterized by higher contents of C16:0, C18:1n9, SFA and MUFA, and lower percentages of C18:2n6 and PUFA.

3.2.3. Colour parameters and $\mathbf{p H}$ values. The external appearance (Fig. 1) of any given food product is certainly among their main acceptability criteria. Thus, the colour parameters ( $L^{*}$ : lightness, $a^{*}$ : redness and $b^{*}$ : yellowness) were evaluated in "pastel de nata" samples before and after being baked (Table 4).

In general, the interaction among PN and ST was significant only in baked samples, as shown by $a^{*}, b^{*}$ and $\mathrm{pH}$ values. Furthermore, PN had a much more noticeable effect (significant differences in all cases) than ST, which caused significant differences only in the case of $L^{*}$ and $\mathrm{pH}$ (in baked samples).

In what concerns the differences among formulations, control samples showed higher $L^{*}$ values (before and after baking), indicating their higher lightness when compared to samples added with either PS or CMF; $a^{*}$ values, in turn, were higher in PNCL samples, which, on the other hand, gave the lowest $b^{*}$ values, before and after baking.

Despite the great similarity among $\mathrm{pH}$ values, it was possible to identify a certain tendency for higher values in samples added with PS and those stored for 2 days.

3.2.4. Quantification of radical scavengers and reducing agents. The average $\mathrm{EC}_{50}$ values for DPPH scavenging activity (considering the mean values for both times) were $124 \pm 5 \mathrm{mg}$ $\mathrm{mL}^{-1}$ of extract for PNCL and $145 \pm 16 \mathrm{mg} \mathrm{mL}^{-1}$ of extract for PNPS. In the reducing power assay, the concentrations providing a 0.5 absorbance $\left(\mathrm{EC}_{50}\right.$ values) were very similar: $123 \pm$ $8 \mathrm{mg} \mathrm{mL}{ }^{-1}$ of extract for PNCL and $161 \pm 34 \mathrm{mg} \mathrm{mL}^{-1}$ of extract for PNPS. It should be highlighted that the $\mathrm{EC}_{50}$ values obtained with PNCL, considering the concentrations incorporated in the prepared products, were very similar to those obtained with the CMF extract itself (considered the same concentration as that used in the prepared PNCL). This indicates that the levels of radical scavengers and reducing agents were not affected after incorporation, frosting, baking and storage.

Among PNC samples, no scavenging activity or reducing effect were detected up to the maximum assayed concentration (200 $\mathrm{mg} \mathrm{mL}^{-1}$ ), thereby indicating a clear increase in radical scavengers and reducing agents in PNPS, which was more noticeable (lower $\mathrm{EC}_{50}$ values) in PNCL.

In addition, the levels of these bioactive components on the baking day were almost entirely maintained in this same for- 


\section{Baking day}

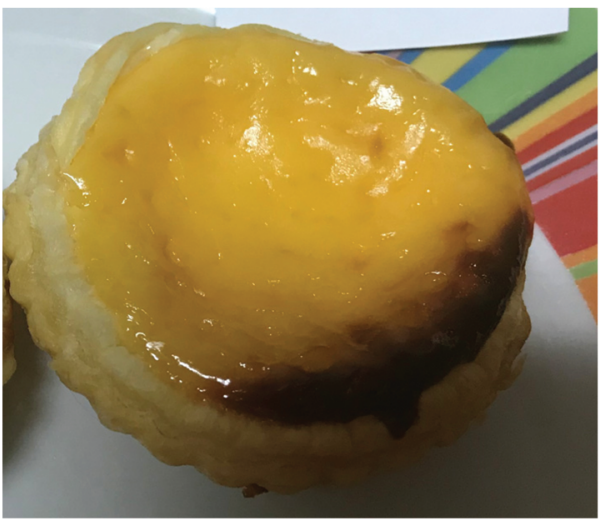

A

B

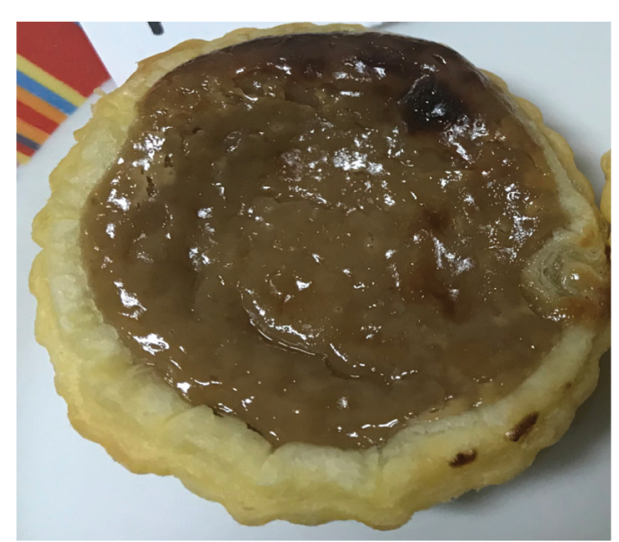

C

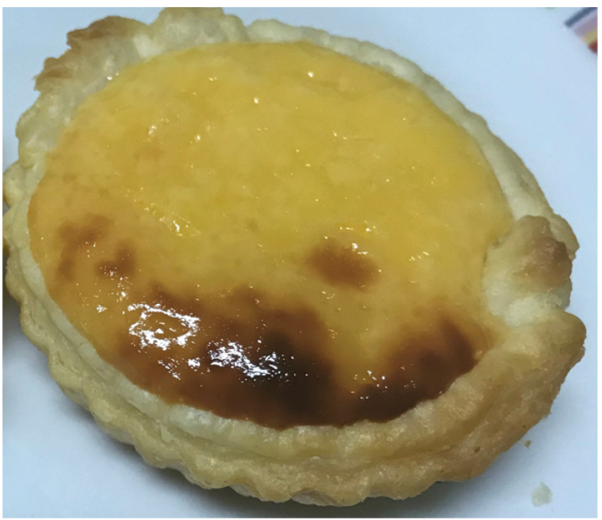

\section{2 days after baking day}
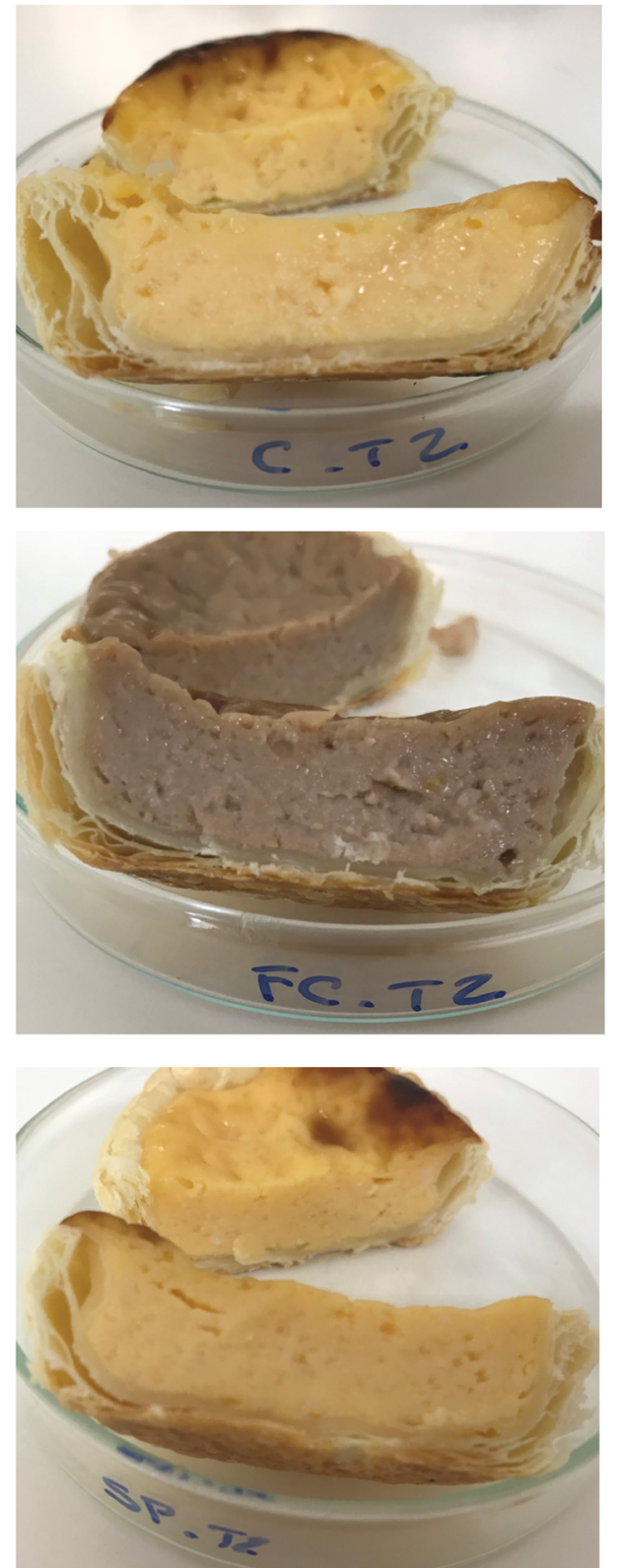

Fig. 1 External appearance of different PN formulations (A) control, (B) "pastel de nata" with CMF; (C) "pastel de nata" with potassium sorbate.

mulation (PNCL): no loss in the DPPH scavenging assay $\left(\mathrm{EC}_{50}=124 \pm 5 \mathrm{mg} \mathrm{mL} \mathrm{m}^{-1}\right.$ of extract in samples assayed on the baking day; $\mathrm{EC}_{50}=125 \pm 5 \mathrm{mg} \mathrm{mL}^{-1}$ of extract in samples assayed 2 days after baking) and 10\% loss in reducing power $\left(\mathrm{EC}_{50}=117 \pm 7 \mathrm{mg} \mathrm{mL} \mathrm{m}^{-1}\right.$ of extract in samples assayed on the baking day; $\mathrm{EC}_{50}=129 \pm 3 \mathrm{mg} \mathrm{mL}^{-1}$ of extract in samples assayed 2 days after baking), while a significant decrease was observed in PNPS: 19\% loss in the DPPH scavenging assay $\left(\mathrm{EC}_{50}\right.$ $=132 \pm 7 \mathrm{mg} \mathrm{mL}^{-1}$ of extract in samples assayed on the baking day; $\mathrm{EC}_{50}=157 \pm 13 \mathrm{mg} \mathrm{mL} \mathrm{m}^{-1}$ of extract in samples assayed 2 days after baking) and 52\% loss in reducing power $\left(\mathrm{EC}_{50}=128 \pm\right.$ $1 \mathrm{mg} \mathrm{mL} \mathrm{m}^{-1}$ of extract in samples assayed on the baking day;
$\mathrm{EC}_{50}=194 \pm 1 \mathrm{mg} \mathrm{mL} \mathrm{m}^{-1}$ of extract in samples assayed 2 days after baking). This observation can be explained by the fact that potassium sorbate is specifically used as an antimicrobial, in contrast to phenolic compounds which are strong antioxidants. $^{3}$

Furthermore, none of the "pastéis de nata" showed cytotoxicity up to the maximal assayed concentrations $(400 \mu \mathrm{g}$ $\mathrm{ml}^{-1}$ ) and the quantities of trigalloyl-HHDP-glucoside and quercetin-3-O-glucuronide (PNCL) were also maintained along ST, which could be considered as an indicator of the maintenance of the antimicrobial activity (in line with that observed in the case of the antioxidant activity). 
Table 4 Colour parameters evaluated in "pastel de nata" formulations (PN) and storage times (ST). Results are presented as mean \pm standard deviation $^{a}$

\begin{tabular}{|c|c|c|c|c|c|c|c|c|c|}
\hline & & \multicolumn{2}{|l|}{$L^{*}$} & \multicolumn{2}{|l|}{$a^{*}$} & \multicolumn{2}{|l|}{$b^{*}$} & \multicolumn{2}{|l|}{$\mathrm{pH}$} \\
\hline \multirow{3}{*}{ PN } & Chestnut male flower (CMF) extract & $64 \pm 1 \mathrm{c}$ & $58 \pm 4 \mathrm{c}$ & $8.8 \pm 0.4 \mathrm{a}$ & $9.6 \pm 0.3$ & $24 \pm 1 \mathrm{c}$ & $21 \pm 2$ & $6.2 \pm 0.1 \mathrm{c}$ & $6.3 \pm 0.1$ \\
\hline & Potassium sorbate (E202) & $72 \pm 1 \mathrm{~b}$ & $77 \pm 3 b$ & $4.8 \pm 0.3 \mathrm{~b}$ & $3.9 \pm 0.5$ & $39 \pm 1 \mathrm{a}$ & $41 \pm 1$ & $6.4 \pm 0.1 \mathrm{a}$ & $6.4 \pm 0.2$ \\
\hline & ANOVA $p$-value $(n=18)^{b}$ & $<0.001$ & $<0.001$ & $<0.001$ & $<0.001$ & $<0.001$ & $<0.001$ & $<0.001$ & 0.041 \\
\hline \multirow{2}{*}{ ST } & 2 days & $71 \pm 6$ & $75 \pm 10$ & $6 \pm 2$ & $6 \pm 2$ & $32 \pm 6$ & $34 \pm 10$ & $6.3 \pm 0.1$ & $6.5 \pm 0.1$ \\
\hline & $t$-Student $p$-value $(n=27)^{c}$ & 0.902 & 0.021 & 0.976 & 0.539 & 0.988 & 0.211 & 0.204 & $<0.001$ \\
\hline $\mathrm{PN} \times \mathrm{ST}$ & $p$-value $(n=54)^{d}$ & 0.708 & 0.131 & 0.982 & $<0.001$ & 0.979 & $<0.001$ & 0.241 & $<0.001$ \\
\hline
\end{tabular}

${ }^{a}$ The results presented for each PN include values measured in both ST; likewise, results for each ST were obtained considering the values measured in all PN formulations. ${ }^{b}$ If $p<0.050$, the corresponding parameter presented a significantly different value for at least one PN. ${ }^{c}$ If $p<$ 0.050 , the corresponding parameter presented a significantly different value for each ST. ${ }^{d} p<0.050$ indicates a significant interaction among factors, thereby precluding performing multiple comparison tests.

\subsection{Linear discriminant analysis}

In the former sections, changes resulting from PN and ST were evaluated in each parameter individually. As explained, some statistically significant differences were found in specific cases, but the true effects of PN conjugated with ST could be better characterized by identifying the most significant changes induced by both factors, i.e., finding the variables (studied parameters) more highly correlated to the PN and ST levels.

Accordingly, a linear discriminant analysis (LDA) was applied to characterize how PN and ST (categorical dependent variables) were correlated with the complete matrix of results (quantitative independent variables). Independent variables were considered as significant $(p<0.050)$ according to the Wilks' $\lambda$ test, following the stepwise method.

The first three defined discriminant functions justified 98.5\% (first function: $86.6 \%$; second function: $7.8 \%$; third function: $4.1 \%$ ) of results' variance (Fig. 2). Among the 37 studied variables, 9 (fructose, C18:2n6, $L^{*}$ before and after baking, $a^{*}$ after baking, $b^{*}$ before and after baking, DPPH scavenging activity and reducing power) were selected as having significant capacity to discriminate different PN formulations.

The first function presented high correlations with $a^{*}$ (after baking) and DPPH scavenging activity and its main effect was the separation of markers corresponding to PNCL (either assayed on the baking day or two days after), which showed higher $a^{*}$ values and the lowest $\mathrm{EC}_{50}$ values in the $\mathrm{DPPH}$ scavenging assay. Function 2, in turn, was mostly correlated with the reducing power and linoleic acid, contributing mainly to separate markers corresponding to each assayed period in the case of the control and PNPS, mainly due to the decrease in linoleic acid percentage and reducing agents. Function 3 was more highly correlated with $L^{*}$ (before baking), which was lower in PNC, thereby contributing to separate the markers corresponding to this formulation (particularly those assayed two days after baking).

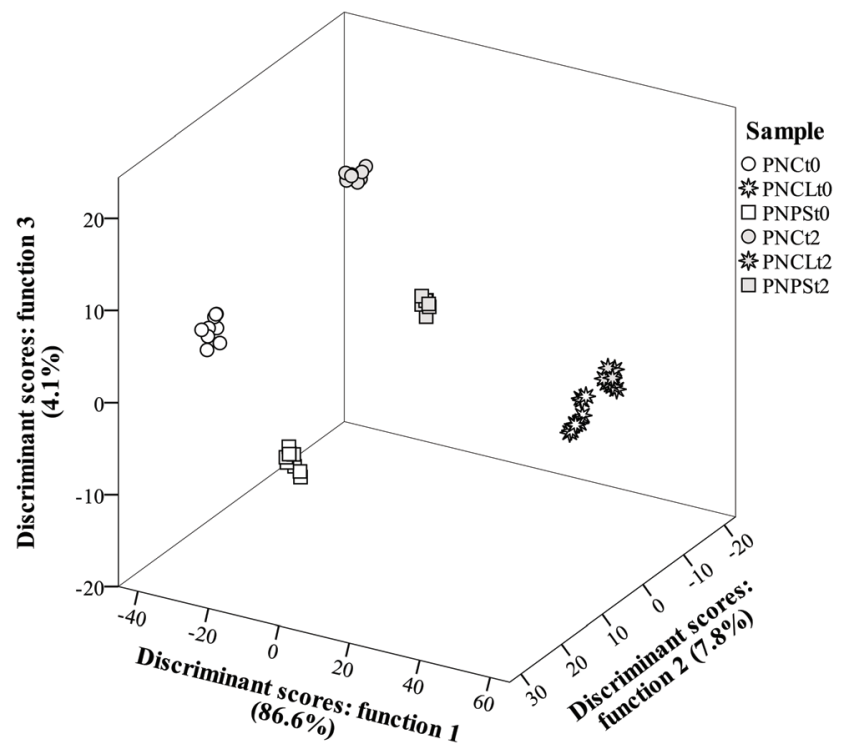

Fig. 2 Canonical discriminant function coefficients defined from the evaluated parameters considering "pastel de nata" formulation and storage time conjugated effects.

The model performance was evaluated by verifying the accurate classification of original grouped and cross-validated cases, which was $100 \%$ correct in both cases.

\section{Conclusions}

In general, PNCL had enough differences from PNC and PNPS (particularly in fructose, C18:2n6, $L^{*}$ before and after baking, $a^{*}$ after baking, $b^{*}$ before and after baking, DPPH scavenging activity and reducing power). In addition, and in contrast to what was observed with PNC and PNPS, PNCL samples maintain their characteristics throughout the 2-day storage period, 
as depicted in the LDA output (proximity among the PNCL markers corresponding to both periods). Accordingly, CMF proved to be a suitable alternative as a natural preservative to be applied in the Portuguese delicacy "pastel de nata".

\section{Conflicts of interest}

There are no conflicts to declare.

\section{Acknowledgements}

The authors are grateful to the Foundation for Science and Technology (FCT, Portugal) and FEDER under Programme PT2020 for financial support to CIMO (UID/AGR/00690/2019); national funding by FCT, P.I., through the institutional scientific employment program-contract for L. Barros and R. C. Calhelha contracts; to the project AllNat for the contract of C. Caleja (Project AllNat POCI-01-0145-FEDER-030463). This work is funded by the European Regional Development Fund (ERDF) through the Regional Operational Program North 2020, within the scope of Project NORTE-01-0145-FEDER-023289: DeCodE.

\section{References}

1 C. Biguzzi, C. Lange and P. Schlich, Effect of sensory exposure on liking for fat- or sugar-reduced biscuits, Appetite, 2015, 95, 317-323, DOI: 10.1016/j. appet.2015.07.001.

2 C. Biguzzi, P. Schlich and C. Lange, The impact of sugar and fat reduction on perception and liking of biscuits, Food Qual. Prefer., 2014, 35, 41-47, DOI: 10.1016/j. foodqual.2014.02.001.

3 M. Carocho and I. C. F. R. Ferreira, A review on antioxidants, prooxidants and related controversy: Natural and synthetic compounds, screening and analysis methodologies and future perspectives, Food Chem. Toxicol., 2013, 51, 15-25, DOI: 10.1016/j.fct.2012.09.021.

4 S. M. S. Farakos and J. F. Frank, Challenges in the Control of Foodborne Pathogens in Low-Water Activity Foods and Spices, in The Microbial Safety of Low Water Activity Foods and Spices, 2014, pp. 15-34, DOI: 10.1007/978-1-4939-2062-4.

5 M. Krystyjan, D. Gumul, R. Ziobro and A. Korus, The fortification of biscuits with bee pollen and its effect on physicochemical and antioxidant properties in biscuits, LWT-Food Sci. Technol., 2015, 63(1), 640-646, DOI: 10.1016/j. lwt.2015.03.075.

6 A. Pasqualone, A. M. Bianco, V. M. Paradiso, C. Summo, G. Gambacorta and F. Caponio, Physico-chemical, sensory and volatile profiles of biscuits enriched with grape marc extract, Food Res. Int., 2014, 65, 385-393, DOI: 10.1016/j. foodres.2014.07.014.

7 J. M. Neves, C. Matos, C. Moutinho, G. Queiroz and L. R. Gomes, Ethnopharmacological notes about ancient uses of medicinal plants in Trás-os-Montes (northern of
Portugal), J. Ethnopharmacol., 2009, 124(2), 270-283, DOI: 10.1016/j.jep.2009.04.041.

8 M. Carocho, L. Barros, A. Bento, C. Santos-Buelga, P. Morales and I. C. F. R. Ferreira, Castanea sativa mill. Flowers amongst the most powerful antioxidant matrices: A phytochemical approach in decoctions and infusions, BioMed Res. Int., 2014, 232956, DOI: 10.1155/2014/232956.

9 M. Carocho, R. C. Calhelha, M. J. R. P. Queiroz, A. Bento, P. Morales, M. Soković and I. C. F. R. Ferreira, Infusions and decoctions of Castanea sativa flowers as effective antitumor and antimicrobial matrices, Ind. Crops Prod., 2014, 62, 42-46, DOI: 10.1016/j.indcrop.2014.08.016.

10 M. Carocho, J. C. M. Barreira, A. L. Antonio, A. Bento, P. Morales and I. C. F. R. Ferreira, The incorporation of plant materials in "Serra da Estrela" cheese improves antioxidant activity without changing the fatty acid profile and visual appearance, Eur. J. Lipid Sci. Technol., 2015, 117(10), 1607-1614, DOI: 10.1002/ejlt.201500018.

11 M. Carocho, J. C. M. Barreira, L. Barros, A. Bento, M. Cámara, P. Morales and I. C. F. R. Ferreira, Traditional pastry with chestnut flowers as natural ingredients: An approach of the effects on nutritional value and chemical composition, J. Food Compos. Anal., 2015, 44, 93-101, DOI: 10.1016/j.jfca.2015.08.003.

12 M. Carocho, J. C. M. Barreira, A. Bento, V. Fernández-Ruiz, P. Morales and I. C. F. R. Ferreira, Chestnut and lemon balm based ingredients as natural preserving agents of the nutritional profile in matured "serra da Estrela" cheese, Food Chem., 2016, 204, 185-193, DOI: 10.1016/j. foodchem.2016.02.136.

13 M. Carocho, J. C. M. Barreira, A. Bento, P. Morales and I. C. F. R. Ferreira, Chestnut flowers as functionalizing agents to enhance the antioxidant properties of highly appreciated traditional pastry, Food Funct., 2016, 5, DOI: 10.1039/c4fo00552j.

$14 \mathrm{~K}$. Fox, The 50 best things to eat in the world, and where to eat them, The Guardian., 2009, Retrieved from, https://www. theguardian.com/lifeandstyle/2009/sep/13/best-foods-inthe-world.

15 C. Caleja, L. Barros, M. A. Prieto, A. Bento, M. B. P. P. Oliveira and I. C. F. R. Ferreira, Development of a natural preservative obtained from male chestnut flowers: Optimization of heat- assisted extraction technique, Food Funct., 2019, 10, 1352-1363, DOI: 10.1039/C8FO02234H.

16 L. Barros, M. Dueñas, M. I. Dias, M. J. Sousa, C. SantosBuelga and I. C. F. R. Ferreira, Phenolic profiles of cultivated, in vitro cultured and commercial samples of Melissa officinalis L. infusions, Food Chem., 2013, 136(1), 1-8, DOI: 10.1016/j.foodchem.2012.07.107.

17 R. Guimarães, L. Barros, M. Dueñas, A. M. Carvalho, M. J. R. P. Queiroz, C. Santos-Buelga and I. C. F. R. Ferreira, Characterisation of phenolic compounds in wild fruits from Northeastern Portugal, Food Chem., 2013, 141(4), 3721-3730, DOI: 10.1016/j.foodchem.2013.06.071.

18 M. Soković, J. Glamočlija, P. D. Marin, D. Brkić and L. J. L. D. Van Griensven, Antibacterial effects of the essen- 
tial oils of commonly consumed medicinal herbs using an in vitro model, Molecules, 2010, 15(11), 7532-7546, DOI: 10.3390/molecules15117532.

19 M. Soković and L. J. L. D. Van Griensven, Antimicrobial activity of essential oils and their components against the three major pathogens of the cultivated button mushroom, Agaricus bisporus, Eur. J. Plant Pathol., 2006, 116(3), 211224, DOI: 10.1007/s10658-006-9053-0.

20 S. M. F. Bessada, J. C. M. Barreira, L. Barros, I. C. F. R. Ferreira and M. B. P. P. Oliveira, Phenolic profile and antioxidant activity of Coleostephus myconis, (L .) Rchb. f.: An underexploited and highly disseminated species, Ind. Crops Prod., 2016, 89, 45-51, DOI: 10.1016/j.indcrop.2016.04.065.

21 AOAC, Official Methods of Analysis, The Association of Official Analytical Chemists International, 2016, 38( (8)), 431.

22 L. Barros, E. Pereira, R. C. Calhelha, M. Dueñas, A. M. Carvalho, C. Santos-Buelga and I. C. F. R. Ferreira, Bioactivity and chemical characterization in hydrophilic and lipophilic compounds of Chenopodium ambrosioides L, J. Funct. Foods, 2013, 5(4), 1732-1740, DOI: 10.1016/j. jff.2013.07.019.

23 A. Fernandes, A. L. Antonio, J. C. M. Barreira, M. B. P. P. Oliveira, A. Martins and I. C. F. R. Ferreira, Effects of gamma irradiation on physical parameters of Lactarius deliciosus wild edible mushrooms, Postharvest Biol. Technol., 2012, 74, 79-84, DOI: 10.1016/ j.postharvbio.2012.06.019.

24 C. Caleja, L. Barros, A. L. Antonio, M. Carocho, M. B. P. P. Oliveira and I. C. F. R. Ferreira, Fortification of yogurts with different antioxidant preservatives: A comparative study between natural and synthetic additives, Food Chem., 2016, 210, 262-268, DOI: 10.1016/j. foodchem.2016.04.114.

25 J. C. M. Barreira, I. C. F. R. Ferreira, M. B. P. P. Oliveira and J. A. Pereira, Antioxidant activities of the extracts from chestnut flower, leaf, skins and fruit, Food Chem., 2008, 107(3), 1106-1113, DOI: 10.1016/j.foodchem.2007.09.030. 